\title{
Coordinated Control Scheme of Battery Energy Storage System (BESS) and Distributed Generations (DGs) for Electric Distribution Grid Operation
}

\author{
Cha, Seung-Tae; Zhao, Haoran; Wu, Qiuwei; Saleem, Arshad; Østergaard, Jacob
}

Published in:

Proceedings of IECON 2012

Publication date:

2012

Document Version

Early version, also known as pre-print

Link back to DTU Orbit

Citation (APA):

Cha, S-T., Zhao, H., Wu, Q., Saleem, A., \& Østergaard, J. (2012). Coordinated Control Scheme of Battery Energy Storage System (BESS) and Distributed Generations (DGs) for Electric Distribution Grid Operation. In Proceedings of IECON 2012 IEEE.

\section{General rights}

Copyright and moral rights for the publications made accessible in the public portal are retained by the authors and/or other copyright owners and it is a condition of accessing publications that users recognise and abide by the legal requirements associated with these rights.

- Users may download and print one copy of any publication from the public portal for the purpose of private study or research.

- You may not further distribute the material or use it for any profit-making activity or commercial gain

- You may freely distribute the URL identifying the publication in the public portal 


\title{
Coordinated Control Scheme of Battery Energy Storage System (BESS) and Distributed Generations (DGs) for Electric Distribution Grid Operation
}

\author{
Seung Tae Cha*, Haoran Zhao*, Qiuwei Wu*, Arshad Saleem**, Jacob Østergaard* \\ *Technical University of Denmark, **Royal Institute of Technology, Sweden \\ stc@elektro.dtu.dk, hzhao@elektro.dtu.dk, qw@elektro.dtu.dk, Arshad.Saleem@ics.kth.se, joe@elektro.dtu.dk
}

\begin{abstract}
This paper describes a coordinated control scheme of battery energy storage system (BESS) and distributed generations (DGs) for electric distribution grid operation. The BESS is designed to stabilize frequency and voltages as a primary control after the electric distribution system enters into the islanding operation mode, while the centralized joint load frequency control (CJLFC) utilizing DGs handles the secondary frequency regulation. The BESS with the associated controllers has been modelled in Real-time digital simulator (RTDS) in order to identify the improvement of the frequency and voltage response. The modified IEEE 9-bus system, which is comprised of several DG units, wind power plant and the BESS, has been employed to illustrate the performance of the proposed coordinated flexible control scheme using RTDS in order to verify its practical efficacy.
\end{abstract}

Key words - Distributed generations (DGs), Battery energy storage system (BESS), Centralized joint load frequency control (CJLFC), Primary/secondary frequency control, Real time digital simulator (RTDS)

\section{INTRODUCTION}

Climate change and new environmental concerns are tremendously influencing and reshaping the future of the power grid around the world. In the past years, this has certainly led to a remarkable and rapid increase in the megawatts produced by intermittent renewable energy resources. These renewable energy resources, including wind and solar generation units, are for the most part intermittent in nature. In this context, Denmark presents a unique opportunity for renewable energy utilization and deployment due to its very pro-active energy policy. As it can be seen in the future energy outlook and policy of Denmark, more renewable energy integration is planned ahead in near future. The long-term Danish government policy aims for 30\% energy production from renewable energies and a goal of approximately $50 \%$ of the average electricity consumption from wind power by 2025 in the visionary Danish energy plan [1]. The central power plant units will be reduced to $4100 \mathrm{MW}$ which will be restricted to $57 \%$ of the current installed capacity. Also, energy strategy 2050 is a huge step towards realizing Danish government's vision of becoming independent of coal, oil and gas. The political objective is $100 \%$ independence of fossil in the long term [2]. On the other hands, wind power generation has reached high levels of penetration in many countries. This can have a negative impact on power systems especially in areas with a weak grid or limited transmission capacities [3]. This future scenario of increased capacity of renewable generation penetrations in the distribution networks will raise significant challenges to the reliability of the system operation and control. And, this trend will indeed continue for the next decades. Any additional increase of wind power capacities could deteriorate system stability. This is in contrast to the general experience and to the goal of many countries to reach higher levels of wind power generation in future. New features addressing the intermittent nature of these resources should be added into power system control and planning, so that systems with smart grids can be operated safely. New regulation solutions have to be implemented in such a future scenario. Possibilities to normalize this problem are an increasing the cross-border transmission lines, demand side response, increased flexibility of conventional power plants, and energy storages [4]. The battery energy storage system (BESS) is among the most efficient and compatible technologies for an improved power system operation and control with large renewable-based electricity generation. The operation of BESS is complementary to the stochastic behaviour of the renewable energy. The BESS can charge whenever there is an excess of electricity in the connected system and discharge when required by the grid. This particular solution is one of the emerging concepts and is the focus of this work as energy storages may become cost effective in future. Recently, the concept of integrating small-size generation units into low voltage distribution networks as an alternative generating source is also gaining popularity, which resulted in large scale deployment of distributed generation (DG) units or high penetration of multiple DG units in power systems. This has certainly brought the concept of the sustainable energy system called micro-grid, where small generating sources located close to load centres are dispersed in the distribution networks. Moreover, in islanded operation mode, with relatively few distributed generations, the frequency and voltage control is not straightforward. The frequency of the micro-grid may change rapidly due to its low inertia present in the micro-grid. Frequency changes in power systems are a direct result of the imbalance between the load and the power supplied by system connected generators. Therefore, load frequency control (LFC) is one of the important issues in islanded power system operation. However, it is a challenge to utilize the DGs within distribution networks both efficiently and economically to assist the islanding operation of the distribution networks. A well designed and operated 
distribution system should cope with changes in the load and system disturbances. It should provide an acceptable high level of power quality in islanding operation while maintaining both frequency and voltage within tolerable limits. The main challenge of operating micro-grid in islanding mode is the coordination of DGs in order to control the system frequency and voltages within the islanded systems. A secondary load frequency control and energy storage systems are needed to maintain the system frequency at the desired nominal value. Many efforts have been dedicated to design novel control strategies for micro-grid operation, especially in islanded mode to correctly manage a micro-grid during its transition from a grid-connected to an islanded operation, as well as during its autonomous operation [5][6]. In [5], a frequency stabilizing system using flywheels has been proposed to the island grid and revealed a great performance for mitigating frequency deviation. The cooperative control scheme of micro sources and an energy storage system during islanded operation is presented in [6]. Also, several projects in Denmark have been investigated by Energinet.dk, the transmission system operator (TSO) [7][8][9]. During this particular project [9], a newly developed real time model for Bornholm power system including an accurate model of thermal and CHP units including governors using RTDS is conducted and a secondary load frequency control scheme has been proposed and thoroughly analysed.

The various sections in this paper are organized as follows. Section II discusses the overview of frequency control in general. Modelling of the modified IEEE 9-bus benchmark system is discussed in Section III. Section IV discusses the coordinated control scheme and the scenarios considered for simulations. The simulation results are presented in Section $\mathrm{V}$ and concluded in Section VI.

\section{FREQUENCY CONTROL CONCEPT}

In this section, the frequency control concept is briefly discussed. The main cause of frequency deviations in power systems is the imbalance between generation and consumption. Classically, three steps are used to describe the control principle. If, for instance, consumption is larger than production, the rotational energy stored in large synchronous machines is utilized to keep the balance between production and consumption. The rotational speed of the generators decrease which in return decrease the system frequency. After a decrease of the system frequency, power plants will immediately release or absorb energy from their rotating mass. The energy stored in this rotating mass is given by the equation 1 .

$$
E=\frac{1}{2} * J * \omega_{m}^{2}
$$

where $J$ is the total inertia of the machine and $W m$ the rotational speed of the machine. As result, the frequency changes. The response is determined by the dynamics of the system and is called 'inertia response', as inertia damps out the frequency deviations.

When the frequency deviation exceeds a pre-defined threshold value, the primary control reacts and changes electric generation output in response to frequency deviations by adjusting the amount of fuel input to the turbine by the governor to restore the power balance subsequent to disturbances or load changes. This function is performed by governors connected to certain generation units, which increase the power output when the frequency drops. Controlling generation units in this manner is referred to as droop control. The droop constant $K_{D}$ is a ratio without dimension and generally expressed as a percentage:

$$
K_{D}=\frac{\frac{-\Delta f}{\frac{f n}{\Delta P_{G}}}}{\frac{P_{G n}}{P_{G}}} \times 100 \%
$$

The primary control should be able to halt the frequency decline/rise and its response time should be within 30 seconds. The drawback of this control method is that when the system reaches steady-state subsequent to a change of system load, then a steady-state frequency error will still persist. This is where the secondary control enters:

Secondary frequency control used to restore the frequency to nominal, subsequent to a change of system load, by changing the load references of the governors. Changing the load reference of governors effectively changes the steadystate frequency in a system. The secondary control should be able to restore the frequency to its nominal value and make the power system to enter a new balance. Its response time should typically be less than 30 minutes [10].

Traditionally, frequency control is carried out on the generator side. However, this is likely to change due to increased capacity of renewable generation - mainly wind power and solar power as mentioned in Section I.

Some new concepts of frequency control and many selfsustainable solutions in the form of heat pumps, electrolyzers, demand response such as demand as frequency controlled reserve (DFR), decentralized intelligent loads (DIL), demandbased frequency control (DBFC), and energy storage are investigated in the Danish context to meet the future regulation power requirements with higher proportions of wind power. A series of new solutions are available to stabilize the frequency under various conditions, including the islanding operation [11][12][13][14].

\section{DESCRIPTION OF BENCHMARK TESTING System}

\section{A. Structure of Power System}

The modified IEEE 9-bus test system is used to illustrate the islanding operation of the distribution grid, and to validate the proposed control scheme. A single line diagram of the modified IEEE 9-bus test system in RSCAD is depicted in Fig. 1. The modified IEEE 9-bus system comprises a $60 \mathrm{kV}$, $50 \mathrm{~Hz}$ grid which feeds an $11 \mathrm{kV}$ network through a $60 / 11 \mathrm{kV}$ transformer. The system consists of three DG units are AGC controlled (regulating units), eight transmission lines, one 
transformer and four loads. Three DG units with nominal power of 4.85 MVA are connected to bus 1, 3 and bus 4, respectively, and simulated with $1.5 \mathrm{MW}$ power output before islanding operation. The loads, totaling $8.5 \mathrm{MW}$, are distributed along the bus 5,6,7,8 and are modeled as constant impedance loads. Parameters of the power system model were from [15]. The benchmark system also consists of a WPP modeled jointly as a 2 MW generation unit plus battery energy storage system (BESS). The WPP and BESS are connected to the grid at the point of common coupling to be utilized when the system transit into islanding operation. Both load and wind speed can also be modified in order to simulate a drop or increase in load demand \& wind power production.

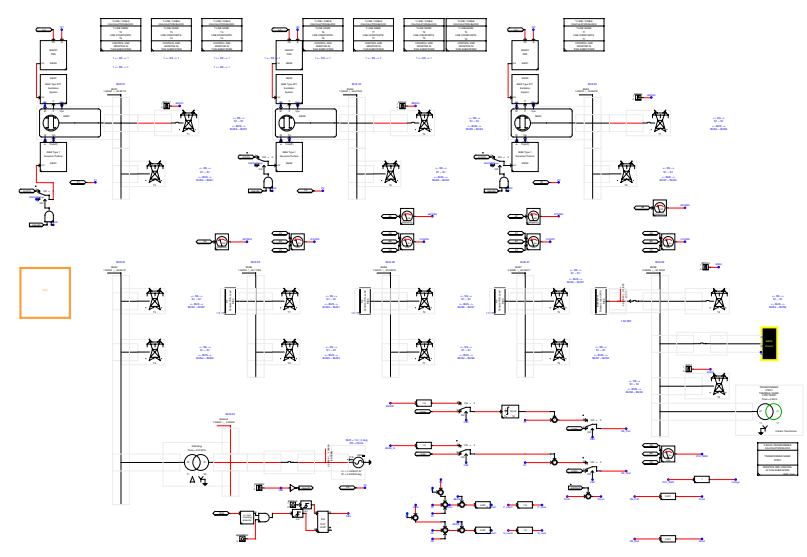

Fig. 1. Modified IEEE 9-bus system built in RSCAD/RTDS

\section{B. Basic Structure of DFIG Wind Power Generation}

The variable speed wind turbine model used in the study system is based on the work of [16]. The principles and mathematical models of DFIG are well documented in literature and hence are only briefly outlined. An interface transformer, a high pass filter and two Voltage Source Converters (VSCs), as well as the DFIG (controls \& wind turbine) are included. The DFIG has become the choice of many utilities for harvesting wind energy due to its ability to provide reactive power support to the power system during low voltage conditions. The DFIG can also extract the optimum wind energy over a wide range of wind speeds, a feature not possible with fixed speed induction generators. The actual DFIG parameters used are typical of a 2 MW, 690 $\mathrm{V}$ machine. The high pass filter is rated at 10 percent of the interface transformer MVA and tuned to remove the switching voltage and current components generated by the VSCs $(21$ x $60 \mathrm{~Hz})$. The grid side VSC operates to control voltage on the capacitor connected between it and the rotor side VSC, while the rotor side VSC controls voltages applied to the rotor to maintain reactive power flow into the DFIG and to control torque. The grid side VSC can also regulate reactive power flow into the system. The wind turbine allows the selection of either of two commonly used power coefficient curves along with user entered parameters. Both wind speed and rotor speed are inputs into the model and mechanical torque is the output. Rotor speed is determined by the DFIG based on inertia and on the difference between mechanical and electrical torques. An optimum torque reference is included to produce maximum power at any rotor speed. Also, a simple pitch control was used to protect the rotor from over speed in the event of strong wind [10].

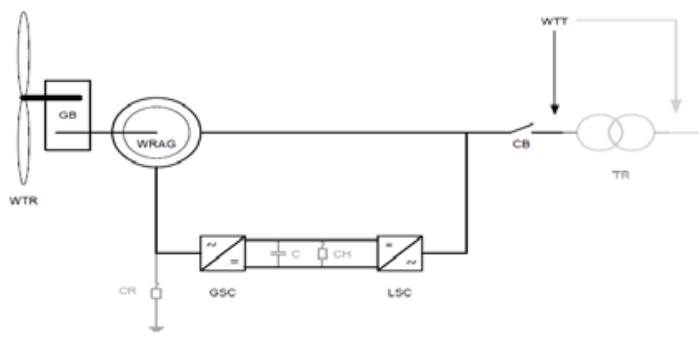

Fig. 2. Structure of DFIG wind power generation

\section{Battery Energy Storage System (BESS)}

The BESS enables smoothing of fluctuations for wind and solar generation units. The system provides a mechanism to store intermittent energy generation, which provides consistent power to the grid. Quick-response characteristic alleviates rapid shifts in renewable energy generation and can therefore act as a frequency regulator. In practice, the BESS consists of rectifier/inverter, battery cells and the Energy Storage System (EMS). The rectifier/inverter is normally based on a voltage source converter (VSC) and a pulse width modulation (PWM). It acts as the interface between DC and AC sides. If the converter losses, internal dynamics of battery cells and battery capacity are ignored, the battery can be regarded as the controlled current sources for three phases. This simplified model is depicted in Figure 3 and implemented in this study. The EMS manages the active and reactive power exchange. There are different control objectives for EMS. Here, the tasks are stabilizing the grid frequency and voltage of the connected bus. Therefore, frequency and voltage are taken as the inputs to determine the active and reactive power references, which equate $d$ and q components of the control signals for the current sources. Considering limitation of the battery power, the derived current control signals have upper and lower limits.

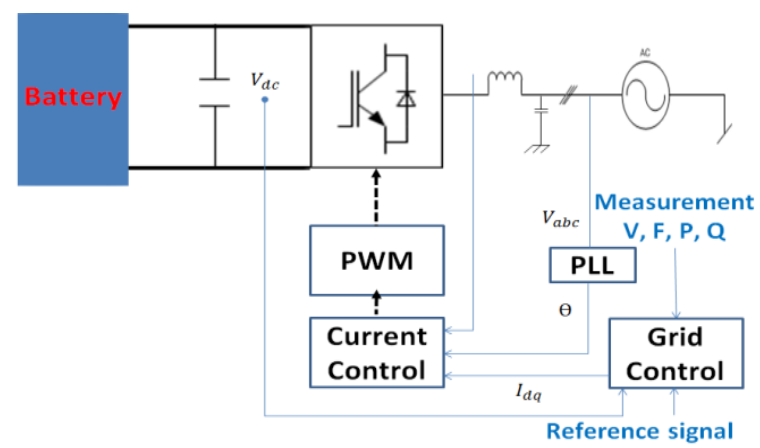

Fig. 3. Simplified BESS model 
IV. COORDINATED CONTROL SCHEME FOR ISLANDING OPERATION OF ELECTRIC DISTRIBUTION SYSTEM

\section{A. BESS Control Strategy}

The main concept for islanding operation involves the coordinated control of the BESS and other DG units, as shown in Figure 4.

1) During the grid-connected operation

The objectives of BESS are maintaining the grid frequency and the voltage. In this operation, these tasks are mainly carried out by the external grid. Therefore, the BESS is not in active state.

\section{2) During the islanded operation}

The power generated by renewable energy sources varies faster than traditional power generation. If there is no BESS, the power balance between the generated power and the existing loads does not always match due to the renewable energy fluctuations. As a result, the frequency and the voltage of the modeled grid will fluctuate. This must be synchronized or it can lead to grid instability under fluctuating frequency conditions. Once the islanded situation is detected, BESS is activated. Clearly, the BESS can provide fast response by proper power balancing as other DG units have a relatively slow response time. Thus, the frequency and the voltage of the grid can be regulated at the nominal values. However, due to its capacity limitation, BESS should be coordinated with CJLFC. According to the proposed scheme, the CJLFC detects the change in the power output of the BESS and assigns the difference to the DG units. This secondary regulation control can reduce the consumption of the stored energy of BESS without degrading the control performance.

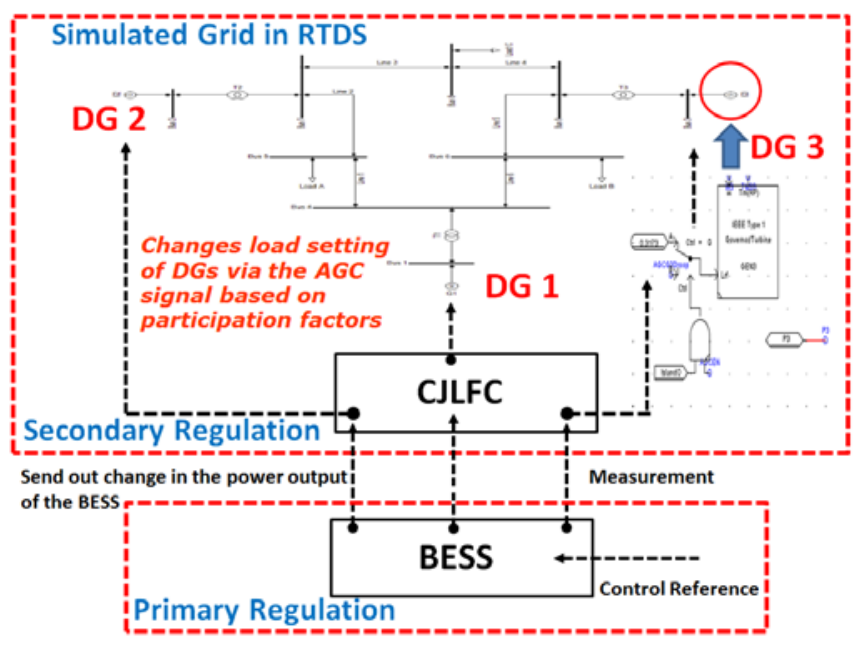

Fig. 4. Coordinated control scheme of BESS and CJLFC

\section{B. Centralized Joint Load Frequency Control}

The secondary load frequency control can be built in a number of ways, either locally or in a centralized and automatic way as represented in Figure 5. The secondary load frequency control is performed as follows. If the system is operating in grid-connected mode, the centralized control is disabled. However, if the grid becomes isolated, then the centralized control must coordinate with BESS. The two main objectives of the secondary control are to keep the system frequency at or close to $50 \mathrm{~Hz}$ and to maintain each DG unit's generation at the most economic value. The centralized join load frequency control is enabled subsequently to the action of local DG units response to an imbalance between load and generation. This imbalance can be caused either by the islanding of the grid or by variations in load. In order to perform load frequency control, the centralized control receives and stores information from the load (load levels), DG units (active power levels) and frequency measurements. Using above frequency deviation as input and based on their participation factors calculated using cost-functions associated with each DG and economic set points. The secondary frequency control implemented in the centralized control specifies the active power set-points that are sent back to the DG units in order to adjust the production levels and consequently correct the frequency offset. The centralized secondary load frequency control structure used in this work is based on the previous author's research [9], and is depicted in Figure 5.

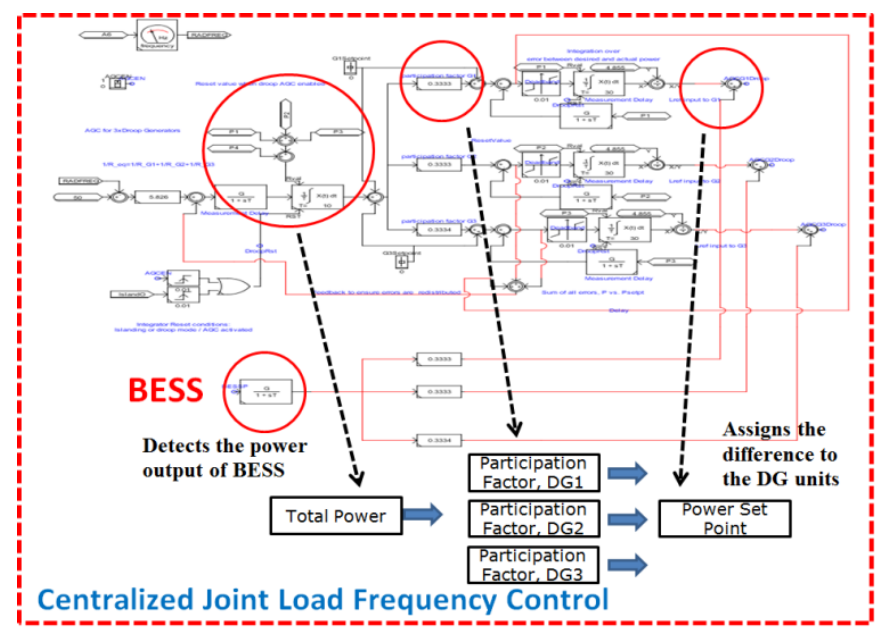

Fig. 5. Centralized joint load frequency control

In this paper, the participation factors can be modified accordingly. For example, it can have all governors share a common load reference (relative to their rated MVA), and then adjust this common load reference, subsequent to a load change in order to restore the frequency to nominal. Or, it can be added to base loads and participation factors. Base load is the minimum load of a generation unit. It is useful if a coal power plant is used for district heating (CHP), it is then required to always supply enough hot water according to heat demand for the consumers, and thus should generate a certain amount of power. Participation factors are the percentage of the system load (minus base load) that each of the generation units is set to supply. For our simulation case, three DG units where none of DG units have a base load, their individual power contribution can be calculated as following: 
DG unit 1:

$P_{G 1}=\left(P_{S Y S}-P_{\text {base Total }}\right) \cdot P f_{G 1}+P_{\text {base } G 1}$

DG unit 2:

$P_{G 2}=\left(P_{S Y S}-P_{\text {base Total }}\right) \cdot P f_{G 2}+P_{\text {base } G 2}$

DG unit 3:

$P_{G 3}=\left(P_{S Y S}-P_{\text {base Total }}\right) \cdot P f_{G 3}+P_{\text {base } G 3}$

The load reference of each DG unit must then be set in order to reach nominal frequency:

$$
\begin{aligned}
& L_{\text {ref G1 }}=\frac{\left(P_{\text {SYS }}-P_{\text {base Total }}\right) \cdot P f_{G 1}+P_{\text {base } G 1}+\frac{1}{R_{1}} \cdot f-f_{0}}{S_{\text {rated }}} \\
& L_{\text {ref } G 2}=\frac{\left(P_{\text {SYS }}-P_{\text {base Total }}\right) \cdot P f_{G 2}+P_{\text {base } G 2}+\frac{1}{R_{2}} \cdot f-f_{0}}{S_{\text {rated }}} \\
& L_{\text {ref G3 }}=\frac{\left(P_{\text {SYS }}-P_{\text {base Total }}\right) \cdot P f_{G 3}+P_{\text {base } G 3}+\frac{1}{R_{3}} \cdot f-f_{0}}{S_{\text {rated }}}
\end{aligned}
$$

The CJLFC scheme, as shown in Fig. 5, measures the system frequency and changes load settings of DGs via the LFC signal. The CJLFC calculates the average power that has to be distributed among the DG units connected to the load frequency controller. The resultant control signal specifies the active power set points to the selected DG units for power production adjustment based on participation factors, $p_{f 1}$, $p_{f 2}, p_{f 3}$, where the sum of the participating factors are equal to unity.

\section{SIMULATION OF ISLAND OPERATION}

In order to further assess the effectiveness of the proposed coordinated control scheme, three simulation cases were performed and compared. The frequency and voltage response is conducted with and without storage after switching to islanding operation and as well as decreasing wind speed variation. The simulation with and without the BESS regulation, where none of the distributed generators participate in the CJLFC is considered as the first or reference case. For the remaining simulation cases, two different scenarios are selected and analyzed. As a second case, the case is similar to the case 1 , but CJLFC is activated. The wind speed variation is considered as a third case during islanding operation. The initial condition for each case is that the load is balanced with the production at exactly $50 \mathrm{~Hz}$. This system initially has about 8.5 MW load. The centralized control is continuously monitoring the voltage \& frequency to respond to any disturbance. A 3-phase fault disconnecting from the utility grid is applied at the nominal operating conditions $\left(P_{s c r}=1 p u, \delta_{0}=0\right.$, initial power flow of $\left.2.5 \mathrm{MW}\right)$ at $t=$ $10 \mathrm{~s}$. The following three different simulation cases are performed.

\section{A. Case I}

The simulation result of the first scenario is presented here, where none of the distributed generators participate in the CJLFC during islanding operation mode. The scenario is characterized by a total load of $8.5 \mathrm{MW}$ and the generation of DGs 4.5 MW, wind 2MW, and external grid supplying 2.5 MW. When the grid is disconnected and only the BESS is activated. The execution sequence is described as follows;

- $\quad$ Step 1. Loss of 2.5 MW power from the grid due to an outage or intentional islanding

- $\quad$ Step 2. Created an imbalance in the islanded part of the network

- $\quad$ Step 3. Observe voltage \& frequency drop

- $\quad$ Step 4. BESS activated

- $\quad$ Step 5. Voltage \& frequency recover

In the Fig. 6, the voltage response without BESS regulation control is shown with legend VolBESS OFF (blue curves) and the voltage response with BESS regulation control is shown with legend VolBESS ON (green curves), respectively. The operation control strategy is to use all three DG units as they provide secondary frequency regulation since there is no primary regulation support from the BESS (blue curves).

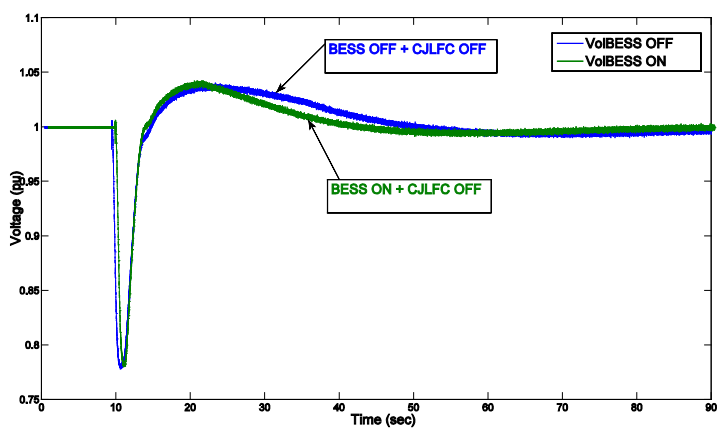

Fig. 6. Voltage response of case I

It is observed that all DGs are switched on to V-f mode after islanding to control the overall island voltage and frequency by sharing or rescheduling between three units based on the participation factors . The output powers of three DGs increase from 1.5 MW to 2.3 MW to consequently correct the frequency offset. As it can be seen from Fig. 6 that the voltage dropped to $0.78 \mathrm{pu}$ and then recovered to the operational range after $46 \mathrm{sec}$ and settled again at $1 \mathrm{pu}$. Therefore, the BESS can improve voltage response of the system. Also, the designed secondary load frequency control is capable of reducing the frequency excursions considerably and keeping it within permissible limits. In the Fig. 7, the stability of the system is maintained and the BESS can effectively stabilize the frequency of the system after switching to islanding operation. The frequency response without BESS regulation control is shown with legend BESS OFF (blue curves) and the frequency response with BESS 
regulation control is shown with legend BESS ON (green curves), respectively. As it can be seen from Fig. 7 that the frequency dropped to $48.99 \mathrm{~Hz}$ and then recovered by the BESS at 56 sec. Even though, the CJLFC is not activated, the frequency is still kept in a very narrow range. The two intervals between times $10 \mathrm{sec}$ to $30 \mathrm{sec}$ show the contribution of the primary frequency control and the time intervals between $30 \mathrm{sec}$ to $65 \mathrm{sec}$ highlight the interests of the secondary frequency regulation. Fig. 7 shows a good contribution of the islanded grid both for primary and secondary frequency control. The BESS ensures that the frequency remains within threshold limits of the power system as evident from the frequency response. In this case, the maximum frequency after islanding event was less severe with BESS than without.

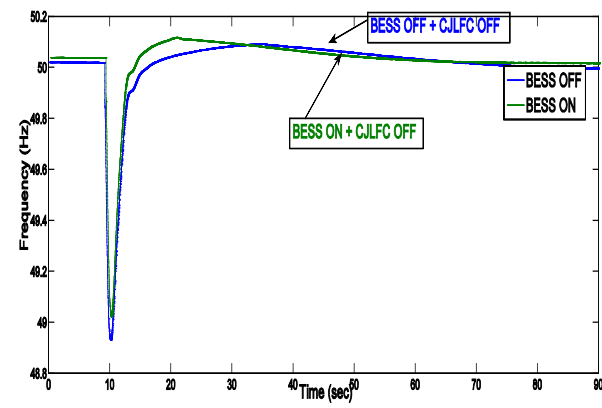

Fig. 7. Frequency response of case I

\section{B. Case II}

The main focus of this case is to further explain the role of BESS and its coordinated control scheme with CJLFC. In the Fig. 8, the power output of BESS changes from zero to a certain value (i.e $0.77 \mathrm{MW}$ ) to control the frequency and the voltages at the instant of disturbance. During this islanding operation, the output power of DG units also changed from an initial values to a new power set points calculated by secondary control, as shown in the Fig. 5 in Section IV. The CJLFC detects the change in the power output of the BESS and assigns the difference to the DG units. This secondary regulation control can reduce the consumption of the stored energy of BESS without degrading the control performance. It is observed that only small amounts of BESS capacity can improve the response of the modeled system. The power BESS injects is shown with legend PBESS ON LFC (blue curves) and the power BESS injects plus the power injections from three DG units with the secondary load frequency control is shown with legend PBESS ON WO (green curves), respectively. As it can be seen from Fig. 8 that the reason for the fact that only $0.77 \mathrm{MW}$ of BESS are requested in the event of islanding operation is that the other DG units also provide frequency regulation and the BESS does not need to contribute or compensate the complete power mismatch. The regulation power requirement from the BESS is also greatly reduced with all DG units participating in load frequency control. The shaded area in the figure (below) represents the total power contributions from three DG units. Moreover,
Fig. 8 indicates that the BESS reacts fast and thus the system is able to reach steady-state operation.

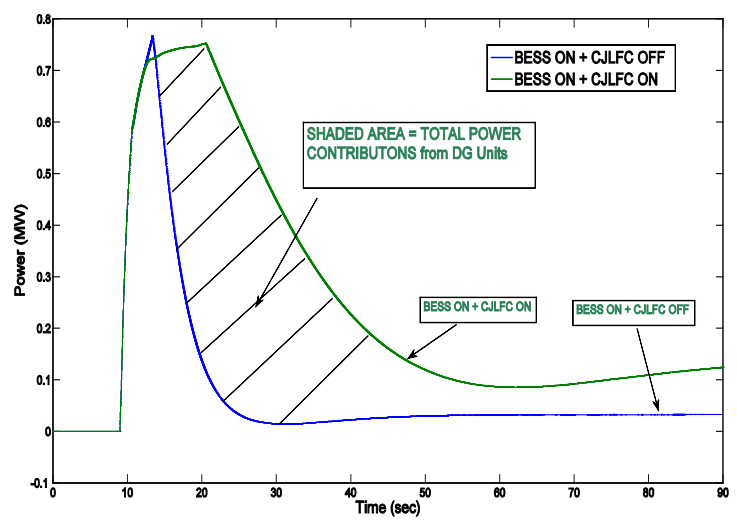

Fig. 8. Response of BESS power output in case II

In this case, the CJLFC was activated which calls the RTDS dynamic simulation computation module. This computation module runs dynamic simulations for a given sample time intervals. At the end of each dynamic simulation, the integral and absolute value of frequency deviation is read from RTDS's output file. Using this information, new power set points are computed and stored in the RTDS's information file for the next dynamic simulation. This process is repeated up to frequency stabilization or a maximum simulation time.

\section{Case III}

The results obtained with wind speed variation are presented in the next four figures. In this particular case, the wind speed was modified from $12 \mathrm{~m} / \mathrm{s}$ to $10 \mathrm{~m} / \mathrm{s}$ while simulation in order to simulate a drop in wind power production (as shown in Fig. 9(a)). The BESS ensures that the frequency and voltage remain within threshold limits of the power system as evident from the Fig. 9(b) and 9(c). Also, it is observed that only small amounts of BESS capacity can improve the response of the modeled system as evident from the Fig. 9(d).
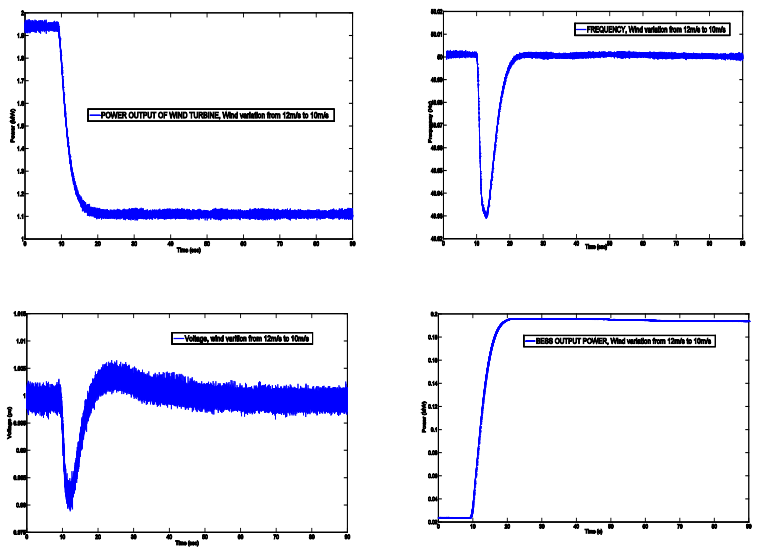

Fig. 9. Response of BESS power output in case 3 (a) wind turbine $P_{\text {out }}$, (b) frequency response, (c) voltage response, and (d) BESS $P_{\text {out }}$ in clockwise 


\section{CONCLUSION}

A coordinated flexible control scheme of the battery energy storage system (BESS) and distributed generators (DGs) for distribution grid operation in the event of islanding mode has been proposed to help stabilize frequency and the voltages of the distribution systems. The BESS is designed to provide frequency support as a fast-acting primary control, and the centralized joint load frequency control (CJLFC) acts as a supplementary to help maintaining the constant frequency and voltage. The case study results with the modified IEEE 9bus system including a WPP and a BESS show that the proposed control scheme can respond very fast and thus can be operated in stable during islanding operation. A real-time digital simulation of the modeled system is carried out. It is observed that only small amount of BESS capacity can improve the system response and the secondary regulation control can also reduce the consumption of the stored energy of BESS without degrading the proposed control performance. Hence, the results indicate the efficiency of the BESS for real-time applications and its suitability for the case considered. In addition, the simulation results presented in this paper can quantify BESS performance both in EMS for real-time operation and in power system planning for future renewable energy resource connections.

\section{ACKNOWLEDGMENT}

The work was supported by the Transmission System Operator (TSO), Energinet.dk, the Distribution System Operator (DSO), Østkraft, Bornholm and Technical University of Denmark (DTU). The authors gratefully acknowledge the support received from Dr. Kim, J. Y, Korea Electro-technology Research Institute.

\section{REFERENCES}

[1] Z. Xu, M. Gordon, M. Lind, and J Østergaard, "Towards a Danish power system with 50\% wind - smart grids activities in Denmark," IEEE Power and Energy Society General Meeting, 2009.

[2] Energinet.dk (2011), "Energy strategy 2050-from coal, oil, and gas to green energy,” Feb 2011.

[3] P. Braun, M. Swierczynski, F. Blaabjerg, "Li-Ion batteries in a virtual power plant (energy storage + wind power plant) for primary frequency regulation", $10^{\text {th }}$ International Workshop on large scale integration of wind power into power system as well as transmission network for offshore wind farms, Oct 2011

[4] T. Ackermann, Wind Power in Power Systems, $1^{\text {st }}$ Edition, Wiley 2005.

[5] K. Yamashita, O. Sakamoto, Y. Kitauchi, "Development of frequency stabilizing scheme for integrating wind power generations into a small island grid,” IFAC World Congress, Oct 2010

[6] J. Y. Kim, J. H. Jeon, "Cooperative control strategy of energy storage system and microsources for stabilizing the microgrid during islanded operation,” IEEE Transactions on Power Electronics, vol. 25 no. 12, 2010, pp. 3038-3048.

[7] Yu Chen, Zhao Xu, and Jacob Østergaard, "Frequency analysis for planned islanding operation in the Danish distribution system Bornholm," UPEC, 2008.

[8] Yu Chen, "Control architecture for intentional islanding operation in distribution network with high penetration of distributed generation," pp. 1-140, Ph.D Thesis, 2010.

[9] Seung Tae, Cha, Qiuwei Wu, Jacob Østergaard "Frequency stabilizing control scheme for a Danish island grid,” in Proc. IEEE Innovative Smart Grid Technologies, 2012, under review.
[10] Seung Tae, Cha, Qiuwei Wu, Arshad S., Jacob Østergaard "Modeling and control for islanding operation of active distribution systems," in book Chapter 3, Springer 2011.

[11] Z. Xu, J. Østergaard, M. Togeby, "Design and modelling of thermostatically controlled loads as frequency controlled reserve," in Proc. IEEE PES General Meeting, 2007, pp. 1-6.

[12] D. Trudowski, M. Donnelly, "Power system frequency and stability control using decentralized intelligent loads," in Proc. IEEE PES Transmission and Distribution Conference and Exposition, 2005, pp. 1453-1459.

[13] J. W. Black, M. Ilic, "Demand-based frequency control for distributed generation," in Proc. IEEE Power Engineering Society Summer Meeting, 2002, pp. 427-432.

[14] A. Madureira, "Secondary load frequency control for microgrids in islanded operation”, in Proc. International Conference on Renewable Energy and Power Quality, ICREPQ 2005.

[15] Seung Tae, Cha, Arshad Saleem, Qiuwei Wu, Jacob Østergaard, "Multi-agent based controller for islanding operation of active distribution networks with distributed generation," in Proc. International Conference on Electric Utility Deregulation and Restructuring and Power Technologies, 2011, pp. 803-810.

[16] R. Pena, G. Asher, J. Clare, "Doubly fed induction generator using back to back PWM converters and its application to variable-speed wind energy generation," in Proc. IEE on Electrical Power Application, 1996, vol. 143, No.3, pp. 231-241. 